\title{
Role of Steel Plate Thickness on the Residual Stress Formation and Cracking Behavior During Flame Cutting
}

\author{
TUOMAS JOKIAHO (D), SUVI SANTA-AHO D, PASI PEURA (D), \\ and MINNAMARI VIPPOLA (D)
}

\begin{abstract}
Thick wear-resistant steel plates are utilized in challenging applications, which require a high hardness and toughness. However, utilization of the thick plates is problematic as they often have nonuniform mechanical properties along the thickness direction due to the manufacturing-induced segregations. In addition, the processing of thick plates commonly involves flame cutting, which causes several challenges. Flame cutting forms a heat-affected zone and generates high residual stresses during the cutting process. In the worst case, flame cutting causes cracking of the cut edge. The aim of this study is to investigate the role of plate thickness on the residual stress formation and cracking behavior when utilizing flame cutting. Residual stress profiles are measured by X-ray diffraction, plates and cut edges and are mechanically tested and characterized by electron microscopy. The results show that thicker plates generate more unfavorable residual stress state during flame cutting. Thick plates also contain segregations, which have decreased mechanical properties. The combination of high residual tensile stresses and segregations increase the risk of cracking during flame cutting. To prevent the cracking, the residual stresses should be lowered by lower cutting speeds and preheating. In addition, manufacturing practices should be aimed at lowering segregation formation in thick plates.
\end{abstract}

https://doi.org/10.1007/s11661-019-05314-w

(C) The Author(s) 2019

\section{INTRODUCTION}

THICK wear-resistant steel plates are utilized, for example, in the mining industry, where a high degree of hardness and toughness is required. In terms of properties and manufacturing, thick steel plates are more complex compared to thin plates. During solidification, liquid steel may cool unequally and the solidification process may proceed at different rates at different locations in the plate. The formation of segregation on the center plane of the plate is caused by the enrichment of alloying elements such as carbon, phosphorus, sulfur, and manganese near the center region of the thick steel plate. The rolling process compresses the regions enriched by alloying elements and nonmetallic inclusions into thin sheets or strips and results in a layered structure. ${ }^{[1,2]}$ There have been several studies related to the mechanical properties of thick steel plates. Yang

TUOMAS JOKIAHO, SUVI SANTA-AHO, PASI PEURA, and MINNAMARI VIPPOLA are with the Materials Science and Environmental Engineering, Faculty of Engineering and Natural Sciences, Tampere University, 33014 Tampere, Finland. Contact e-mail: tuomas.jokiaho@tuni.fi

Manuscript submitted November 7, 2018.

Article published online June 17, 2019 et al. ${ }^{[1]}$ studied 100- and 120-mm-thick steel plates and noticed that the mechanical properties of plates vary depending on the test location in the thickness direction and generally that properties deteriorate toward the center region of the plate. Wang et al. ${ }^{[2]}$ investigated steel plates with thicknesses of $60,90,120$, and $150 \mathrm{~mm}$, and the results indicated that yield strength, ductility, and fracture toughness values decline as the testing position is changed from the plate surface toward the centerline. Additionally, these properties become worse with increasing plate thickness. Wang et al. ${ }^{[3]}$ studied $60-, 80-, 100-, 120-$, and 150-mm-thick plates and indicated that the mechanical properties decrease as the plate thickness increases. It was noted that tensile strength, ductility, impact toughness, and fracture toughness were lower in both the transverse and thickness directions as the plate thickness increases. In addition, mechanical properties and impact strength in the thickness direction have been shown to be inferior to those in the horizontal directions (transverse or rolling direction).

The manufacturing of wear-resistant and thick steel plates includes cutting, which is difficult due to the hardness, toughness, and thickness of the plates. Mechanical cutting is slow and challenging because the plates are often as hard as the cutting tools. Therefore, 
thermal cutting is a commonly utilized method in the steel industry for cutting thick wear-resistant steel plates. In particular, flame cutting is preferred as it is suitable for thick plates and high production rates. The flame cutting process is exothermal and generates large amounts of heat during the cutting. The generated heat supports the continuity of the cutting process and enables the cutting of very thick steel plates. ${ }^{[4]}$ The flame cutting process includes three stages: First, the steel is locally heated to its ignition temperature by using an oxyfuel gas flame. Second, a jet of pure oxygen is directed to the locally heated area. The oxygen jet causes rapid burning of the steel, thus, cutting through the steel plate. Third, the oxygen jet blows away the iron oxide from the cut edge and exposes clean surfaces for further cutting. ${ }^{[5]}$

Due to the inherent characteristics of the flame cutting process, a notable heat-affected zone (HAZ) is formed near the cut edge of the steel plate. In the HAZ, hardness variations and microstructural and specific volume changes take place. Wood ${ }^{[6]}$ studied 25-mm-thick, low-carbon and low-alloy steel plates and noticed that flame cutting produced a higher hardness region close to the cut edge and the hardness values decreased with increasing distance from the cut edge. Similar findings were reported by Martín-Meizoso et al. ${ }^{[7]}$ who also studied the flame cutting of $25-\mathrm{mm}$-thick steel plates. Wilson ${ }^{[8]}$ studied the flame cutting of 25.4-, 50.8-, and 101.6-mm-thick plates and indicated that a higher cutting speed generated narrower HAZ and higher hardness. It was also reported that plates with an increased amount of alloying elements tend to produce harder and broader HAZ. In addition, in an earlier study, ${ }^{[9]}$ it was confirmed that the flame cutting process creates three types of microstructural regions in the HAZ: a martensite region, two-phase region (mixture of newly formed martensite and tempered original structure), and tempered original structure. The region closest to the cut edge is fully austenized during the flame cutting, and during cooling, it transforms into martensite. Behind the newly formed martensite region, there is a two-phase region, which is partly austenized during flame cutting and during cooling forms martensite while the nonaustenized regions are tempered. The rest of the HAZ structure consists of the tempered original structure, and the tempering effect gradually decreases with increasing distance from the cut edge.

In addition to microstructural changes, flame cutting generates residual stresses near the cut edge of the plate. Residual stresses are internal stresses that exist in the component even after the external applied loads are removed. Residual stresses originate from a local misfit inside the solid body, such as local plastic deformation, which is balanced by local elastic strains. ${ }^{[10]}$ In flame cutting, the residual stresses can be classified as thermal stresses and transformation stresses. Thermal stresses are caused by different thermal expansions and contractions that occur during heating and cooling. Local thermal expansion and contraction is restrained by the cold surrounding regions, leading to plastic deformation in restrained regions and residual stresses. Transformation stresses arise from local phase transformations, which cause volume changes in these regions. For example, martensite transformation includes volumetric expansion, which can be incoherent with the other microstructural regions and thus create residual stresses. ${ }^{[1]}$ Often residual stresses are grouped into three types (types I, II, and III residual stresses) depending on the range they affect and over which they self-equilibrate. Type I is a macrostress, which varies over large distances, and equilibrates on a macroscopic scale. Types II and III are microstresses, which vary and equilibrate on a microscopic scale. Type II stresses exist in the grain scale, and they usually occur in polycrystalline structures. Type III stresses vary on atomic scale and often originate from dislocations and point defects. Usually, for example, in the hole drilling method, only type I residual stresses are measured as type II and III stresses are averaged to zero within the sampled area. However, it has been noted that in diffraction-based measuring methods, where a particular phase or grain orientation is sampled, type II residual stress can be superimposed on the type I stress. ${ }^{[10]}$

In the worst-case scenario, flame cutting leads to cracking of the cut edge. The crack size can be several centimeters long. Commonly cracks are formed in the horizontal (sheet) plane, but they may also propagate in the vertical direction. In an earlier study ${ }^{[9]}$ by the current author, it was found that cracks are often formed just beneath the flame cut surface and for that reason they are difficult to detect. The cracking probability has been noticed ${ }^{[12]}$ to enhance with increasing plate hardness and thickness. In addition, Lindgren et al. ${ }^{[12]}$ reported that high residual tensile stresses promote crack formation. It was shown that a residual compressive stress area is formed close to the cut edge, which is followed by a high residual tensile stress area deeper in the component. It was also noted that a slower cutting speed and flame cutting with preheating produce a lower residual stress state in the cut edge. Similar results were obtained in other studies ${ }^{[13,14]}$ by the author; the residual stress formation during flame cutting can be affected by the size of the sample and cutting parameters. In addition, preheating not only decreases the residual stresses in general but also increases the compressive stress region close to the surface by shifting the tensile stress region deeper into the subsurface.

This study is a continuation for previous studies by the current author. The first study ${ }^{[14]}$ confirmed that the residual state of the flame cut edge can be affected by variating the cutting parameters. In another study, ${ }^{[13]} \mathrm{a}$ model was developed to investigate the flame cut process and residual stress formation. It was used for example to investigate the thermal histories and residual stress formation of the modeled sample during flame cutting. The combination of preheating and low cutting speed produced the most beneficial residual stress state with the most compressive stress and the lowest tensile stress peak. To obtain further knowledge of the flame cut process and cracking behavior, another study ${ }^{[9]}$ was made to investigate the microstructural characteristics related to this topic. It was shown that a higher residual stress state was caused by elongated prior austenite 
grains compared to an equiaxed prior austenite grain structure. In addition, the cracking probability is higher with an elongated prior austenite grain structure compared to equiaxed prior austenite grains. The elongated prior austenite grain structure is susceptible to cracking as it creates grain boundary chains, which can act as possible paths for crack formation. However, despite the studies mentioned earlier, there is still a considerable lack of knowledge on how the plate thickness affects the residual stress formation and cracking in flame cutting. The aim of this study is to determine the effect of the steel plate thickness on the residual stress formation and on the cracking probability. To achieve this goal, wear-resistant steel plates of varying thickness were mechanically tested, flame cut in controlled conditions, and inspected with ultrasound to evaluate the cracking tendency. After this the resulting residual stress state as well as the changes in the microstructure near the cut edge were characterized. The results of this study can be utilized to avoid the cracking of the plates during flame cutting and to improve the manufacturing of thick plate products.

\section{EXPERIMENTAL PROCEDURE}

The studied samples were aluminum-killed, hot-rolled, wear-resistant steel plates. The plate thicknesses of the examined samples were 20, 40, and $60 \mathrm{~mm}$ (width $150 \mathrm{~mm}$, length $150 \mathrm{~mm}$ ). One side of each sample was flame cut utilizing an oxyfuel propane gas flame. The flame cutting parameters applied are shown in Table I. The preheating at $200{ }^{\circ} \mathrm{C}$ (holding time $\sim 1 \mathrm{~h}$ ) of the 40 and $60-\mathrm{mm}$ plates was performed in an industrial furnace under a normal air atmosphere, and the plate temperature was verified by a radiation thermometer. After flame cutting, the samples were inspected using Phasor XS 16/ 16 Olympus ultrasonic equipment with a MSEB 4 dual probe $(4 \mathrm{MHz})$. The ultrasonic inspection results were verified by having two individual researchers repeat the inspections and by sectioning a few samples after inspection to confirm the existence of defects. The nominal composition of the studied sample material is presented in Table II, and the carbon equivalent is

\section{Table I. Flame Cutting Parameters of the Studied Samples}

Flame Cutting Parameters

\begin{tabular}{lcc}
\hline Thickness $(\mathrm{mm})$ & Cutting Speed $(\mathrm{mm} / \mathrm{min})$ & Preheating $\left({ }^{\circ} \mathrm{C}\right)$ \\
\hline 20 & 150 & - \\
20 & 300 & - \\
20 & 500 & - \\
20 & 700 & - \\
40 & 150 & - \\
40 & 300 & - \\
40 & 500 & 200 \\
40 & 500 & - \\
60 & 150 & - \\
60 & 300 & - \\
60 & 500 & 200 \\
60 & 500 & \\
\hline
\end{tabular}

calculated with Ito and Besseyo (1), which covers low ranges of carbon $(<0.18 \mathrm{wt}$ pct $\mathrm{C})$. Steels with over 0.4 wt pet $\mathrm{CE}$ cannot be easily welded because of their increased tendency to form martensite. ${ }^{[15]}$

Residual stress measurements were performed using an XStress 3000 X-ray diffractometer (manufactured by Stresstech Oy) by the modified Chi method. ${ }^{[16]}$ The residual measuring method is described in more detail in previous studies. ${ }^{[9,13,14]}$ The examination locations and directions of the residual stress measurements are described in Figure 1. As shown in the figure, measurements were performed at the centerline of the samples (where the cracks are mostly formed during flame cutting) in two perpendicular measurement directions: the rolling direction ( $0 \mathrm{deg})$ and the thickness direction (90 deg). The selected directions are the most important orientations from crack formation point of view.

Sectioned flame cut samples were analyzed using scanning electron microscopes (SEMs). Grinding of the samples were done with abrasive $\mathrm{SiC}$ papers and polishing with $3-\mu \mathrm{m}$ and $1-\mu \mathrm{m}$ diamond suspensions. After grinding and polishing, the samples were etched using 4 pct Nital solution. Microstructural characterization was performed using a Philips XL-30 SEM and a Zeiss ULTRAplus field emission SEM (FE-SEM). The prior austenite grain sizes (PAGS) were measured from the micrographs of the centerline and two-phase region by mean linear intercept $\left(L_{\mathrm{M}}\right)$. Hardness profiles $(\mathrm{HV} 5 \mathrm{~kg})$ in the thickness direction of the plates were obtained using a Struers DuraScan 80, whereas the hardness depth profiles (HV $0.2 \mathrm{~kg}$ ) from the flame cut edge were carried out using a digital microhardness tester Matsuzawa MMT-X7. The location of the hardness depth profiles in relation to the cut edge is presented in Figure 1. Tensile tests in the thickness direction for each plate were performed with an MTS $250 \mathrm{kN}$, according to the EN-ISO 6892-1 standard. ${ }^{[17]}$ The samples were round bars with an original diameter (D0) of 6,10 , and $10 \mathrm{~mm}$ and parallel length $\left(L_{\mathrm{c}}\right)$ of 11,22 , and $42 \mathrm{~mm}$ for the 20-, 40-, and 60-mm-thick plates, respectively. Charpy $\mathrm{V}$-notch impact tests were performed according to the EN-ISO 148-1 standard ${ }^{[18]}$ with specimens sectioned into square bars with dimensions of $10 \mathrm{~mm} \times 10 \mathrm{~mm} \times$ $55 \mathrm{~mm}$. The studied samples were in the longitudinal and transverse directions in relation to the rolling direction with test temperatures of $-40^{\circ} \mathrm{C},-20{ }^{\circ} \mathrm{C},-10^{\circ} \mathrm{C}$, $0{ }^{\circ} \mathrm{C}$, and $20^{\circ} \mathrm{C}$. In addition, samples from $40-$ and $60-\mathrm{mm}$ plates were made from both the 0.5 and 0.25 thicknesses (longitudinal and transverse directions). The $60-\mathrm{mm}$ plates were also tested with samples made in the thickness direction at temperatures of $-10{ }^{\circ} \mathrm{C}, 0{ }^{\circ} \mathrm{C}$, $22{ }^{\circ} \mathrm{C}$, and $60{ }^{\circ} \mathrm{C}$. The impact test results presented in this study are an average of six repetitions. The test location and directions of this study are presented in Figure 1.

\section{RESULTS}

The mechanical properties of the steels under study were determined by means of hardness measurements and tensile tests. The results presented in Table III show that the average hardness (hardness profiles in the 
Table II. Nominal Composition of the Studied Steel Plates and Carbon Equivalent (CE) ${ }^{[15]}$ for Studied Material

\begin{tabular}{|c|c|c|c|c|c|c|c|c|}
\hline $\mathrm{C}(\mathrm{pct})$ & $\mathrm{Si}$ (pct) & $\mathrm{Mn}$ (pct) & $\mathrm{Cr}(\mathrm{pct})$ & Mo (pct) & $\mathrm{Ni}(\mathrm{pct})$ & $\mathrm{Cu}(\mathrm{pct})$ & $\mathrm{V}(\mathrm{pct})$ & $\mathrm{B}(\mathrm{pct})$ \\
\hline $\begin{array}{l}0.15 \\
\mathrm{CE}=W\end{array}$ & $\begin{array}{c}0.6 \\
\frac{\mathrm{Si}}{0}+\frac{W_{\mathrm{Mn}}+}{}\end{array}$ & $\begin{array}{c}1.1 \\
\mathrm{Cr}+\frac{W_{\mathrm{Ni}}}{60}+\end{array}$ & $\begin{array}{c}0.6 \\
\frac{W_{\mathrm{v}}}{10}+5 W_{\mathrm{I}}\end{array}$ & $\begin{array}{c}0.4 \\
\mathrm{ct}=0.3\end{array}$ & 0.2 & 0.02 & 0.06 & 0.0016 \\
\hline
\end{tabular}

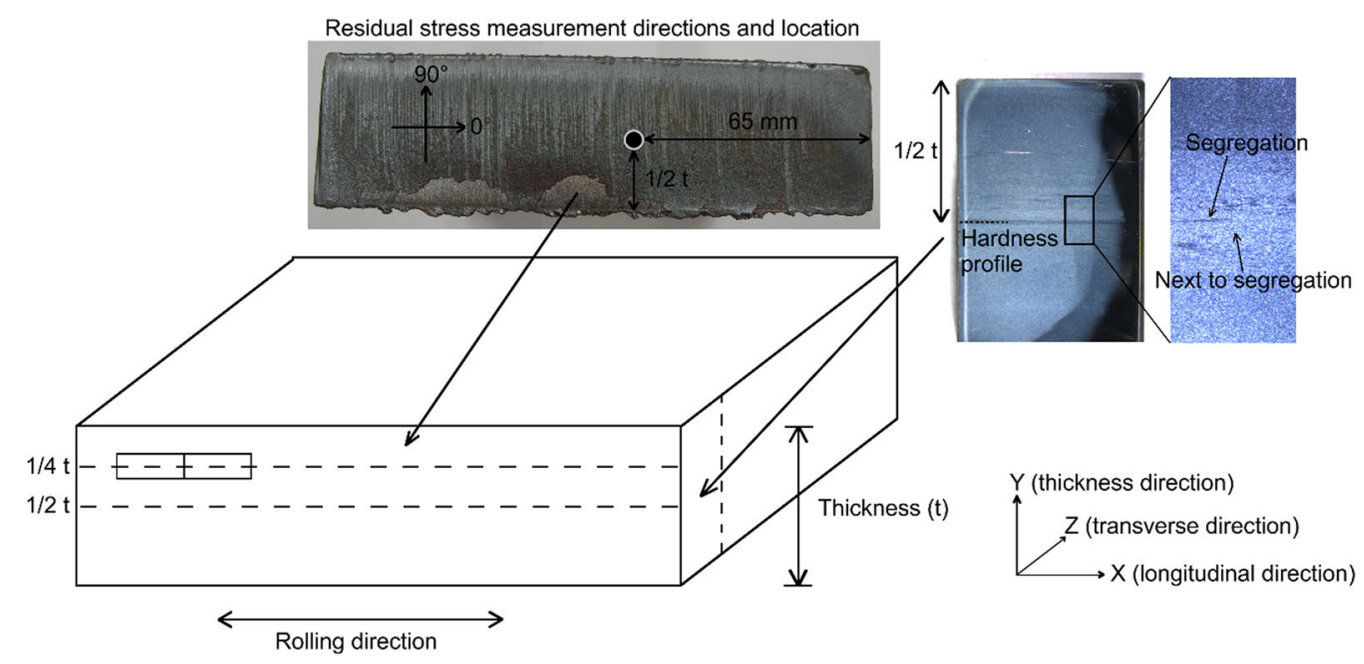

Fig. 1-Test and measurement locations and directions used in this study.

Table III. Initial Mechanical Properties of Studied Steels

\begin{tabular}{lcccc}
\hline Thickness & Hardness $(\mathrm{HV} 5 \mathrm{~kg})$ & $R_{\mathrm{m}}(\mathrm{MPa})$ & $Z(\mathrm{pct})$ & PAGS $L_{\mathrm{M}}(\mu \mathrm{m})$ \\
\hline $20 \mathrm{~mm}$ & 448 & 1347 & 46 & 16 \\
$40 \mathrm{~mm}$ & 399 & 1217 & 51 & 44 \\
$60 \mathrm{~mm}$ & 378 & 1063 & 56 & 54 \\
\hline
\end{tabular}

The average hardness values (HV $5 \mathrm{~kg}$ ), tensile strength $\left(R_{\mathrm{m}}\right)$, and percentage reduction of the area at fracture $(Z$ pct) in tensile tests (thickness direction). Prior austenite grain size (PAGS) is expressed as the mean linear intercept $\left(L_{\mathrm{m}}\right)$ calculated from the centerline micrographs of the studied steels.

thickness direction) of the plate decreases as the thickness increases. Similar observations can be made in the case of the tensile strength $\left(R_{\mathrm{m}}\right)$. The percentage reduction of the area fracture $(Z$ pct $)$ is the lowest in the $20-\mathrm{mm}$ plate and the highest in the $60-\mathrm{mm}$ plate. Furthermore, as is evident from the $\mathrm{Z}$ values, all the studied steels exhibit ductile behavior in the as-received state. In addition, Table III shows that the prior austenite grain size (PAGS) is the smallest with the 20-mm plate and increases with larger plate thicknesses.

SEM micrographs from the centerline of the steel plate samples are presented in Figure 2. The centerline structure of the $20-\mathrm{mm}$ plate sample consists of lath martensite (Figure 2(a)). The structure of the $40-\mathrm{mm}$ plate sample in the centerline consists of a mixture of bainite and lath martensite (Figure 2(b)). The centerline microstructure of $60-\mathrm{mm}$ plates consists mainly of bainite (Figure 2(c)). However, there may also be a small amount of lath martensite in the centerline microstructure of the $60-\mathrm{mm}$ plate.

The hardness values presented in Table III are an average of the hardness profiles measured in the thickness direction of the studied plates. Figure 3 presents the hardness profiles (ten profiles from each sample) along the thickness direction of the 20-, 40-, and $60-\mathrm{mm}$ plates. Hardness profiles from the $20-\mathrm{mm}$ plate indicate a few hardness peaks in the middle section of the plate. In the $40-\mathrm{mm}$ plate, there is more fluctuation in the hardness values in the middle section compared to in the $20-\mathrm{mm}$ plate hardness profiles. There are not only hardness peaks but also softer regions in the thickness range of 15 to $25 \mathrm{~mm}$. The hardness profiles of the $60-\mathrm{mm}$ plate show a steady decrease in hardness with increasing distance from either the top or the bottom surface of the plate toward the center of the plate. The center region ( 25 to $35 \mathrm{~mm})$ consists of low hardness regions with high hardness peaks. In general, the profiles 

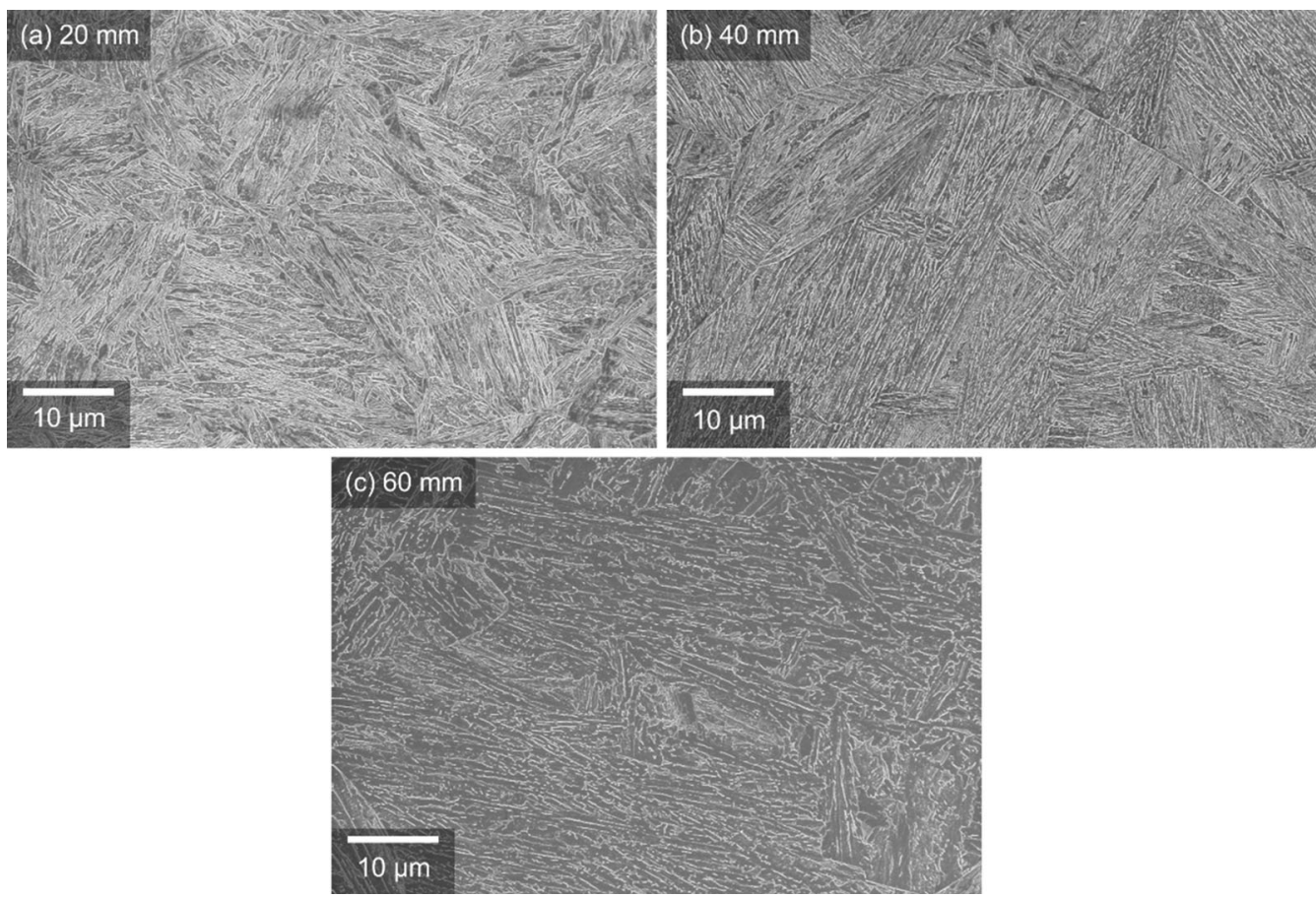

Fig. 2-SEM micrographs of steel plate samples (a) $20 \mathrm{~mm}$, (b) $40 \mathrm{~mm}$, and (c) $60 \mathrm{~mm}$.

in Figure 3 show that the fluctuations in hardness values increase as the plate thickness increases.

Charpy V-notch impact tests were carried out to determine the impact toughness properties of the studied steel plates. As indicated in Figure 4, for all the tested steel plates, the results are similar between the longitudinal and transverse directions in relation to the rolling direction. However, the impact toughness values (longitudinal and transverse in 0.5 thickness) are higher in the $40-\mathrm{mm}$ plates compared to in the $20-\mathrm{mm}$ plates. A comparison of the $40-$ and $60-\mathrm{mm}$ plates shows that the 40-mm plates have higher impact toughness values in 0.5 thickness, whereas in 0.25 thickness, the situation is reserved. In other words, in the tested cases, for the $40-\mathrm{mm}$ plate, the highest impact toughness is measured at 0.5 thickness and for the $60-\mathrm{mm}$ plate at 0.25 thickness. In addition, impact toughness tests were performed in the thickness direction for the $60-\mathrm{mm}$ plates, and the results were much lower compared to the transverse and longitudinal directions (Figure 4).

The impact tests in the thickness direction were performed in two different notch locations (average of three repeats per notch location): in the segregation and next to segregation regions as shown in Figure 1 (the location of segregation was determined from the etched specimens). Figure 5 shows that the impact test location has an effect on the impact energy values. Samples that had a notch in the segregation region have somewhat lower impact toughness properties compared to samples that had a notch next to the segregation. Figure 6 shows SEM micrographs of the fracture surfaces at the segregation (a) and next to the segregation (b) at test temperatures of $-10{ }^{\circ} \mathrm{C}, 0{ }^{\circ} \mathrm{C}, 22^{\circ} \mathrm{C}$, and $60{ }^{\circ} \mathrm{C}$. The fracture surfaces from both test locations have brittle fracture characteristics (examples are shown in Figure 6 with black arrows) such as cleavage planes and river patterns. In addition, in Figure 6(a), the fracture surface at the test temperature of $-10{ }^{\circ} \mathrm{C}$ contains an intergranular fracture region. With increasing test temperature, fracture surfaces contain an increasing amount of ductile fracture characteristics such as dimples (examples are shown in Figure 6 with white arrows). In addition, fracture surfaces at the segregation (Figure 6(a)) show more brittle fracture characteristics compared to fracture surfaces next to the segregation (Figure 6(b)).

Figure 7 presents the results of the residual stress measurements. It can be seen (Figures 7(a), (c), and (f)) that the $20-\mathrm{mm}$ plates have the largest compressive stress region close to the cut edge $(<1 \mathrm{~mm})$ and that the compressive stress values decrease as the plate thickness increases. In addition, the $20-\mathrm{mm}$ plate has the lowest residual tensile stress values compared to the 40- and $60-\mathrm{mm}$ plates at a cutting speed of $150 \mathrm{~mm} /$ minute. However, as the cutting speed increases to 300 and $500 \mathrm{~mm} /$ minute, the tensile stress peak values are almost identical, with only small variations between the studied plate thicknesses. The $20-\mathrm{mm}$ plate has the highest tensile stress peak at a cutting speed of $300 \mathrm{~mm} / \mathrm{minute}$. Figures 7(b), (d), and (f) compare the residual stresses produced by different cutting parameters in the case of each plate thickness. It can be seen that $150 \mathrm{~mm} /$ minute produces the most compressive stresses at the cut edge and the lowest tensile stress region in the $20-\mathrm{mm}$ plates. However, with regard to higher cutting speeds, a very high speed of $700 \mathrm{~mm} /$ minute causes the lowest tensile stress region. In addition, the tensile stress peak at $700 \mathrm{~mm} /$ minute is not as wide as the peaks at the 300 - 

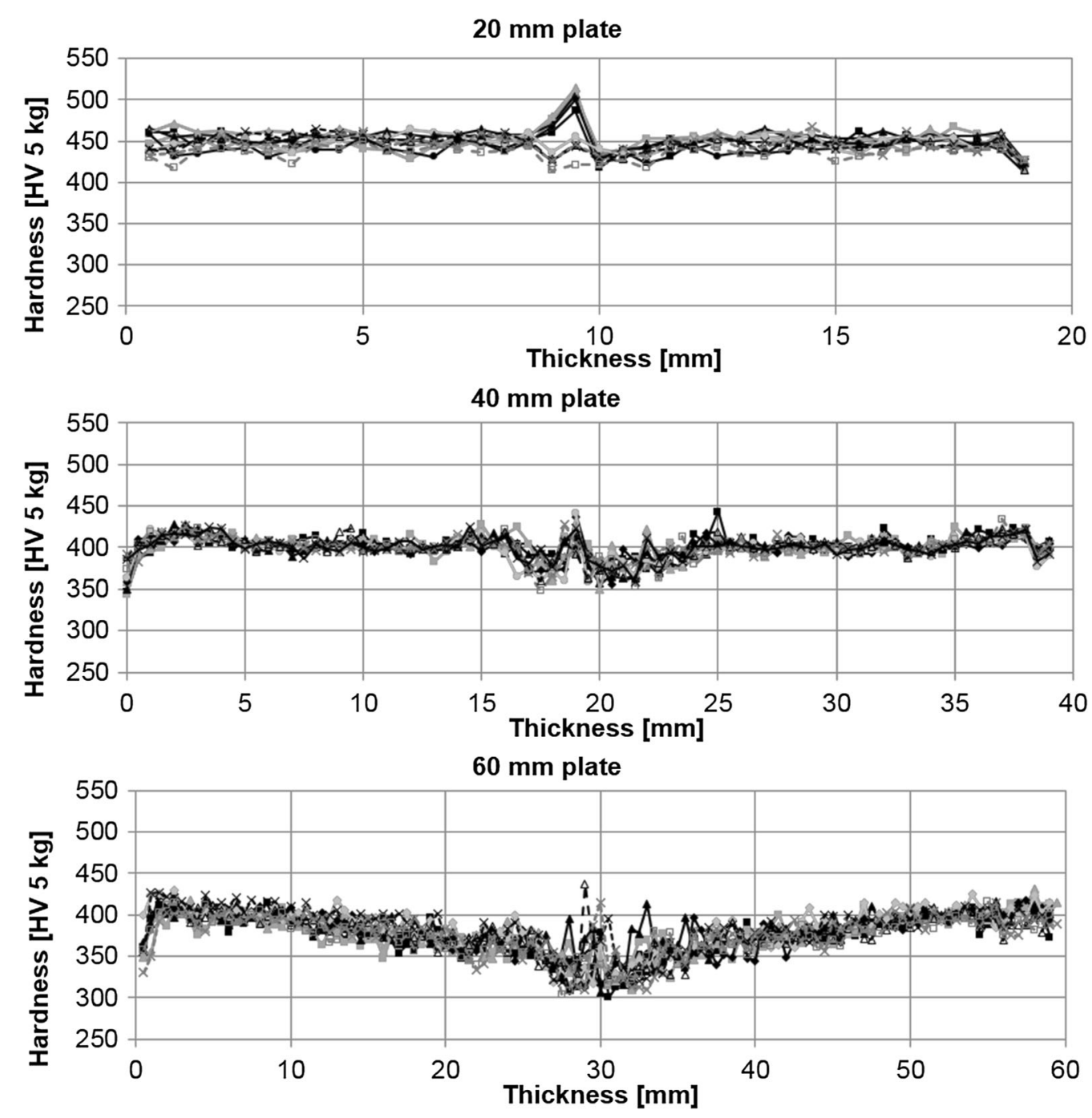

Fig. 3-Hardness profiles (HV $5 \mathrm{~kg}$ ) in the thickness direction in the studied plate thicknesses: 20, 40, and 60 mm (note the different thickness scale in each hardness profile).

and $500-\mathrm{mm} /$ minute cutting speeds. The low $150-\mathrm{mm} /$ minute cutting speed produces the highest residual compressive stress in the $40-\mathrm{mm}$ plates as well. However, the tensile stress values are similar at all cutting speeds. In the $40-\mathrm{mm}$ sample, preheating produces more compressive stress in the surface region but does not affect the tensile stress peak. In the $60-\mathrm{mm}$ plates, the $150-\mathrm{mm} /$ min cutting speed also produces the most compressive stress in the surface. As in the case of the $40-\mathrm{mm}$ samples, the tensile stress peak values are similar between the cutting speeds of 150,300 , and $500 \mathrm{~mm} /$ minute. However, in the $60-\mathrm{mm}$ sample, preheating increases the compressive stress near the surface and lowers the tensile stress deeper in the plate.

Figure 8 presents the hardness profiles measured from the flame cut edges of the studied steel plates. Each flame cut sample produced a high hardness region near the cut edge, after which the hardness levels start to decrease around 0.7 to $0.9 \mathrm{~mm}$ from the cut edge. The lowest hardness values are located after the hardness drop, and subsequently, the hardness gradually increases toward the hardness of the original structure. However, after the lowest hardness values, the increase in hardness is less in the $40-\mathrm{mm}$ plates than in the $20-\mathrm{mm}$ plates and the hardness levels are almost constant in the $60-\mathrm{mm}$ plates after the hardness drop. Figure 8 shows that a slow cutting speed produces a slightly wider high hardness region near the cut edge. As the cutting speed increases, the width of the high hardness region decreases. However, the differences are not significant between different cutting speeds.

Flame cutting creates an HAZ in the cut edge of thick wear-resistant steel plates with three distinct microstructural regions: a martensite region, two-phase region, and tempered original structure. ${ }^{[9]}$ In addition, preheated samples had similar microstructural regions as samples that were flame cut without preheating. The region closest to the cut edge is fully austenized during flame cutting and forms martensite during rapid cooling. This region was similar for all the studied plate thicknesses. Figure 9 shows the martensite regions formed in the cut edge of the 20-, 40-, and 60-mm-thick plates using a 

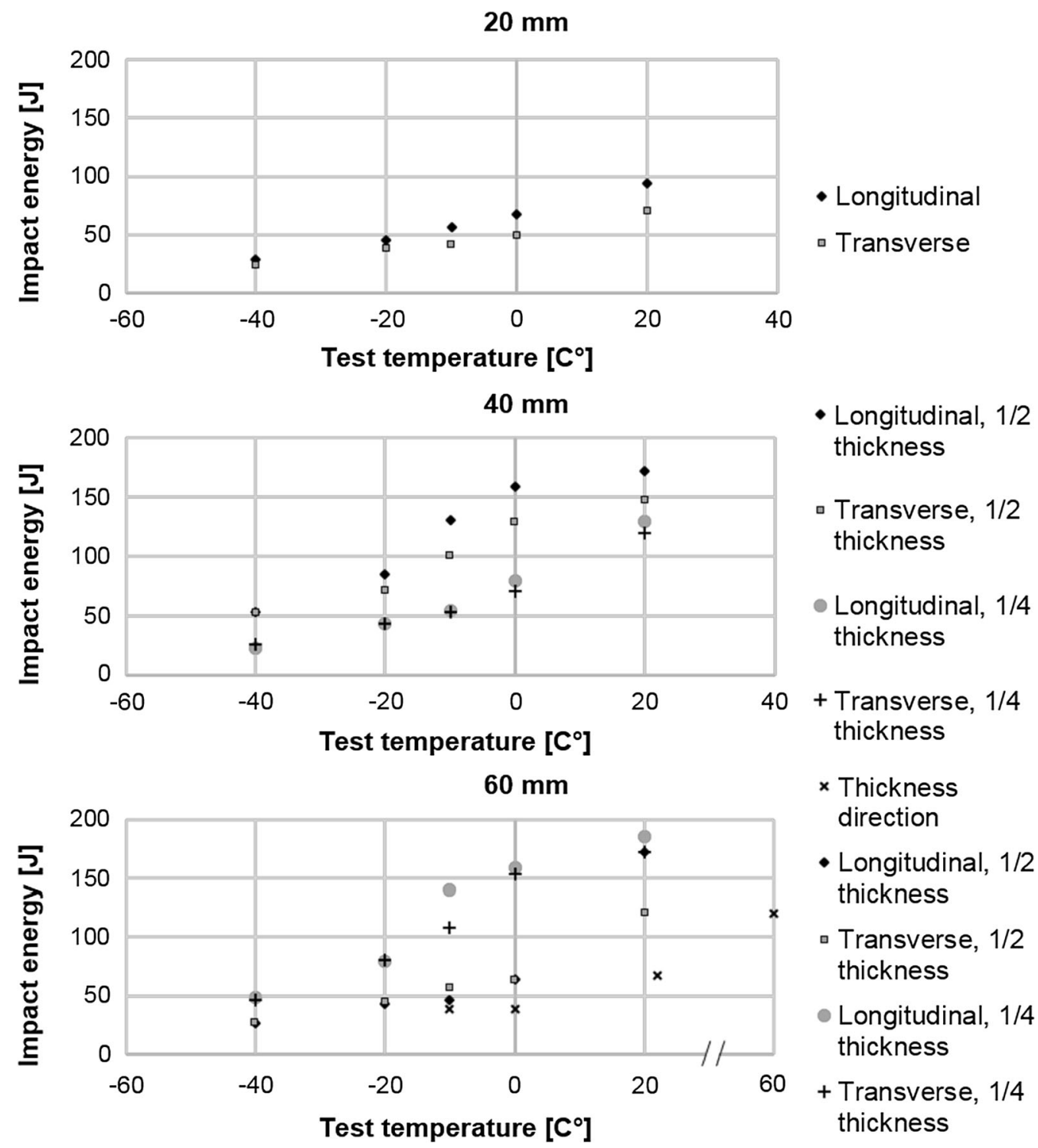

Fig. 4 - Charpy V-notch impact test results in longitudinal and transverse directions in relation to the rolling direction. In addition, the 60-mm plate was also tested in the thickness direction (note different temperature scale in 60-mm results).

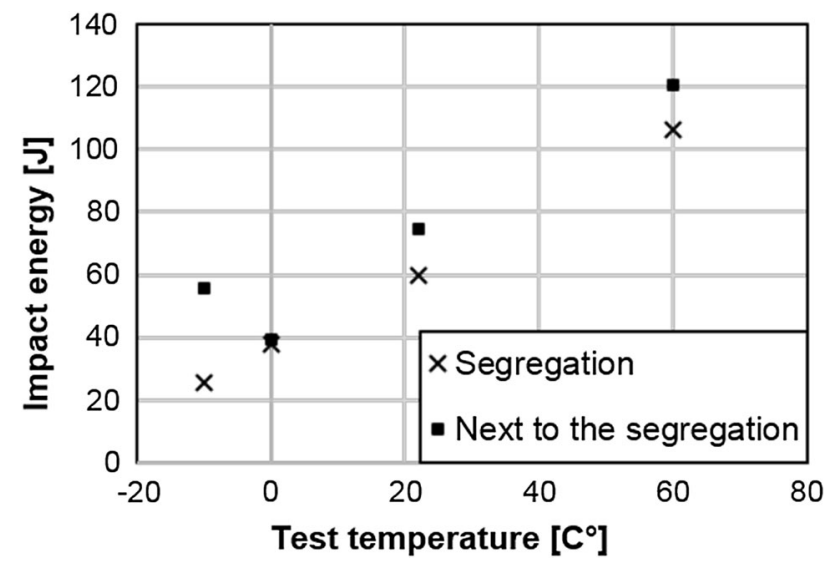

Fig. 5-Charpy V-notch impact tests in the thickness direction with specific notch locations (segregation and next to the segregation) of the $60-\mathrm{mm}$ plate samples. cutting speed of $300 \mathrm{~mm} /$ minute. The image locations were from the centerline of the sample and from a depth of $0.4 \mathrm{~mm}$ from the cut surface.

After the newly formed martensite, there is a two-phase region consisting of martensite and a tempered original structure. The austenization occurs heterogeneously in the grain boundaries of the prior austenite, and during cooling, the austenized regions form a fine martensite lath structure in the two-phase region. The rest of the structure, between the austenized regions, is tempered during the cutting process. Figure 10 shows the two-phase regions from the centerline of the studied 20-, 40-, and 60-mm plates produced by a cutting speed of $300 \mathrm{~mm} /$ minute.

After the two-phase region, the rest of the HAZ consists of the original structure, which is tempered during the cutting process. The tempering effect is gradually reduced while going deeper into the 

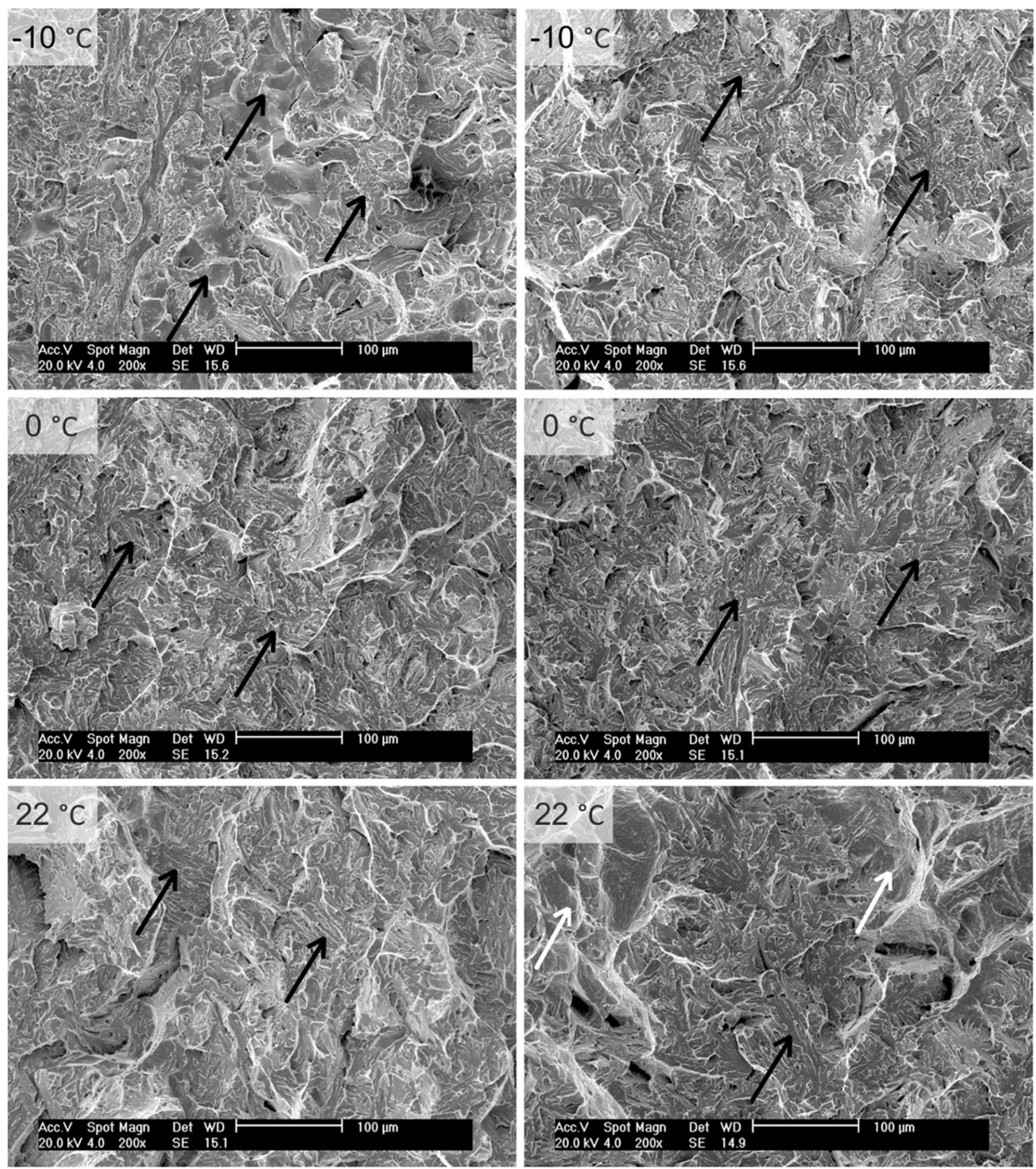

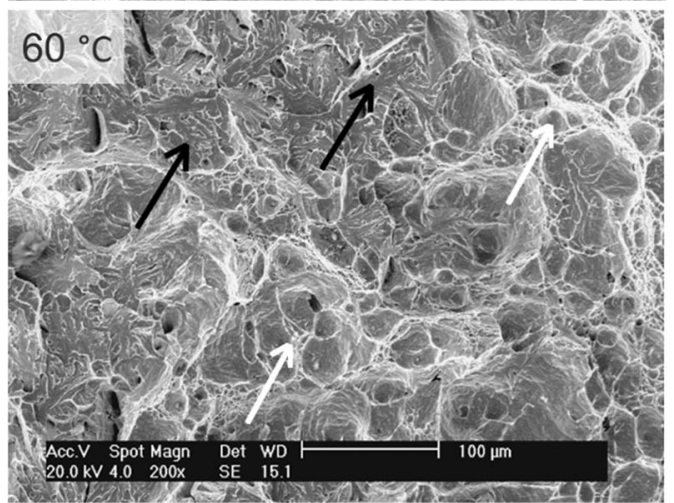

(a)

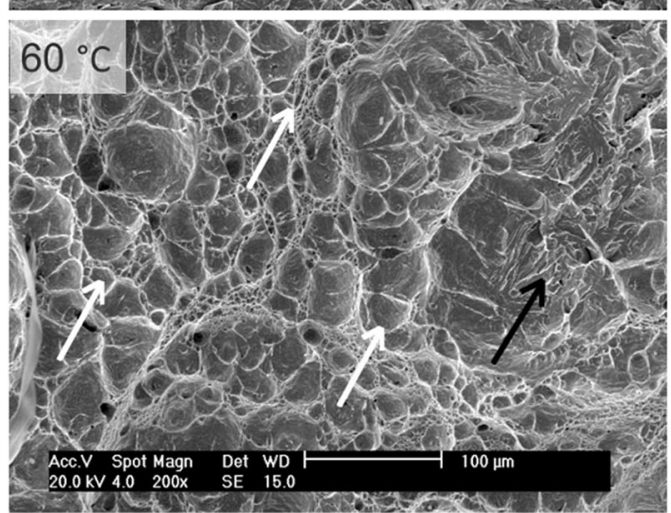

(b)

Fig. 6-Fracture surfaces of Charpy V-notch impact tests in the thickness direction of the 60-mm sample: notch location (a) at the segregation and $(b)$ next to the segregation. Examples of brittle fracture and ductile fracture characteristics are marked in the images with black and white arrows, respectively. 

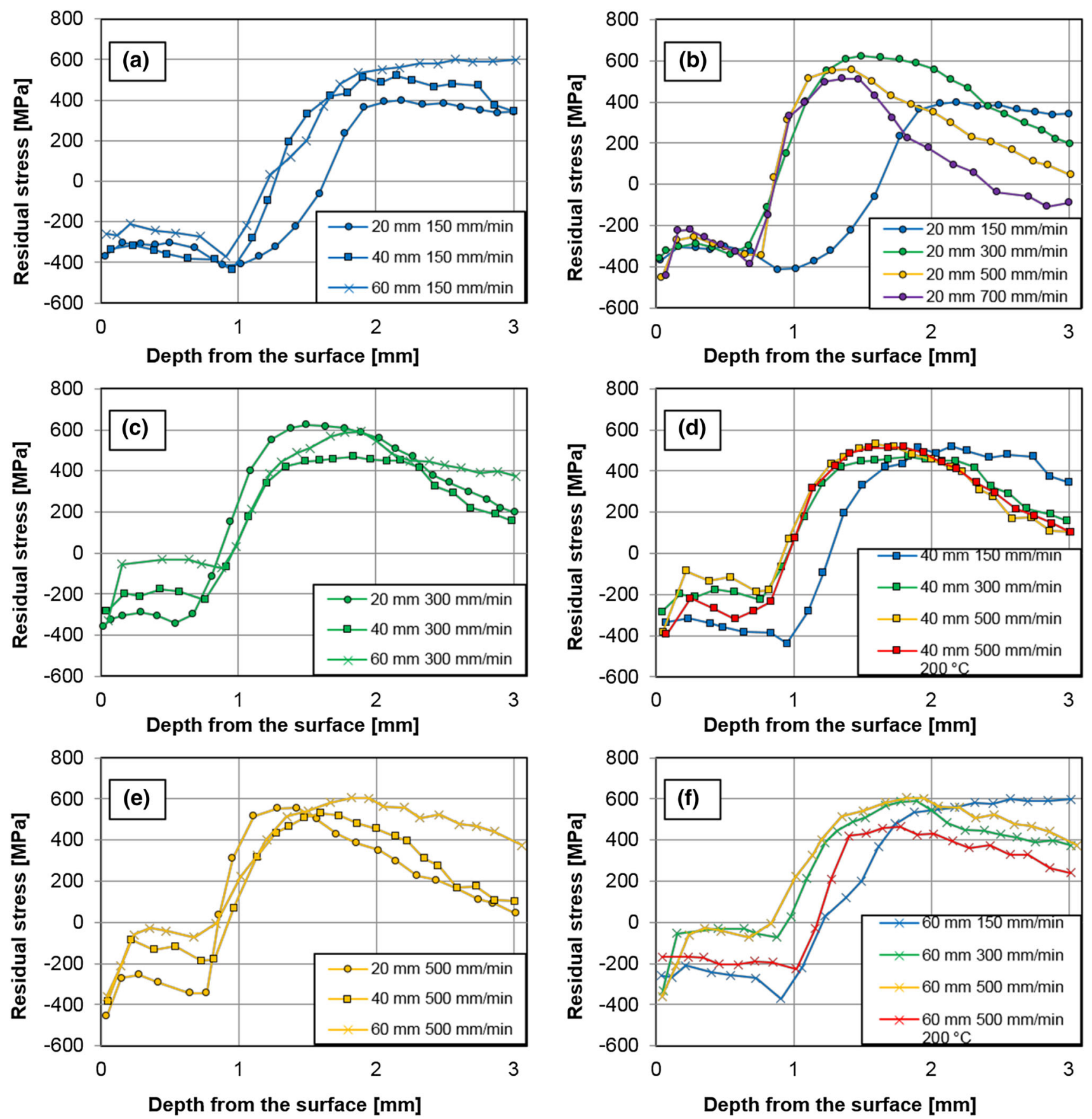

Fig. 7-Residual stress profiles in the thickness direction $\left(90^{\circ}\right)$. The effect of thickness in residual stress profiles at cutting speeds of $(a)$ 150, $(c)$ 300 , and $(e) 500 \mathrm{~mm} / \mathrm{min}$. The effect of cutting parameters in residual stress profiles with certain steel thicknesses: (b) 20, (d) 40 , and $(f) 60 \mathrm{~mm}$. (For interpretation of the color references in these figures, the reader is referred to the web version of this article).

subsurface. Figure 11 shows the centerline micrographs of the studied 20-, 40-, and 60-mm plates from the tempered region (1.6 $\mathrm{mm}$ from the cut surface), which is formed using a $300-\mathrm{mm} /$ minute cutting speed.

The samples were inspected by ultrasound after flame cutting. As presented in Figure 12, no cracks were detected in the $20-\mathrm{mm}$ plates after flame cutting.
However, the inspection revealed three (1 crack/ $1600 \mathrm{~mm}$ ) and four cracks (1 crack/975 mm) in the 40and $60-\mathrm{mm}$ plates, respectively. It should also be noted that no cracks were detected in the preheated samples. The cracks that were found were located immediately below the cut surface in the center region (i.e., near the midplane) of the plates. The crack normal was parallel to the thickness direction of the plate. 

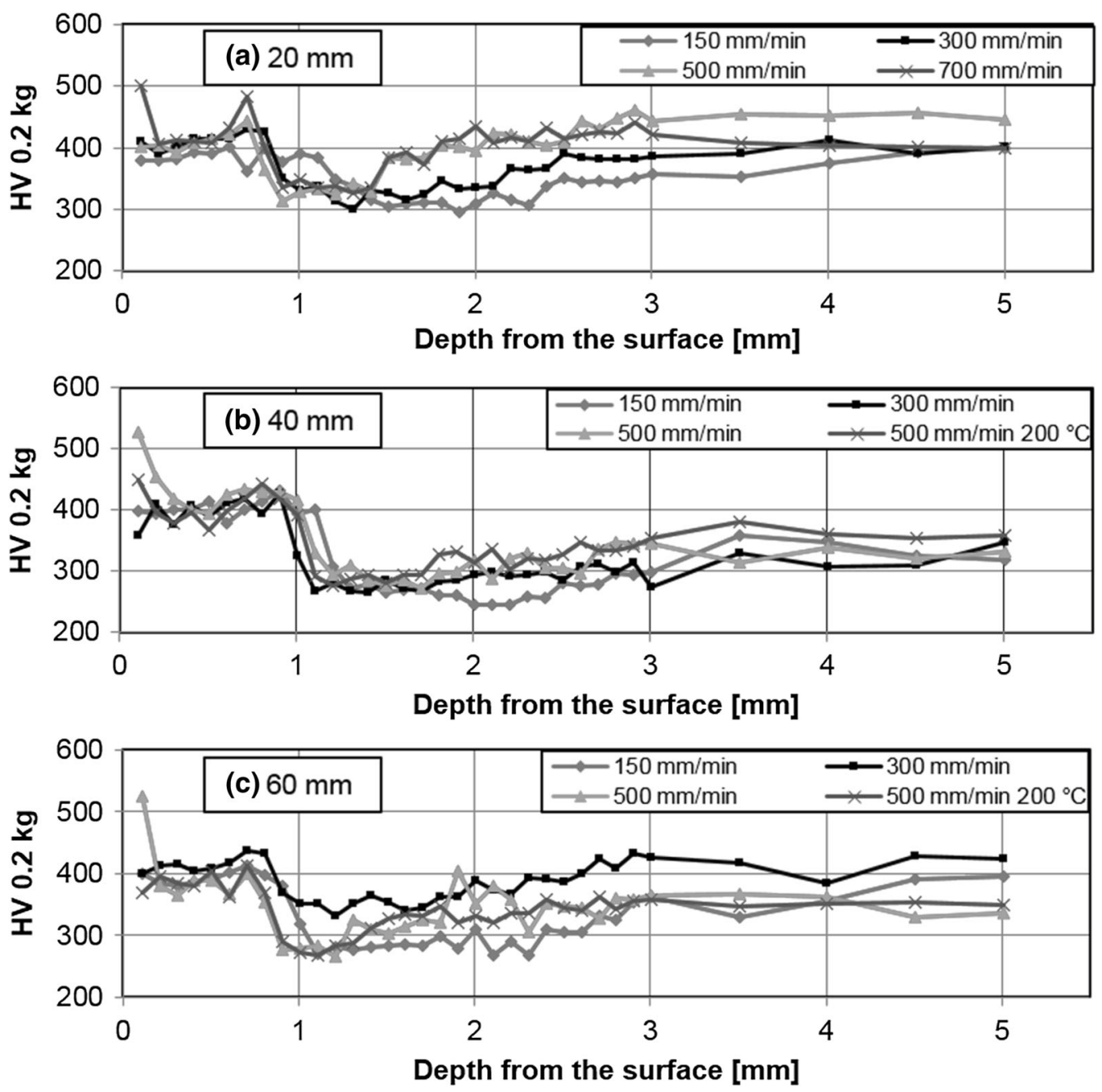

Fig. 8-Hardness depth profiles of studied plate thicknesses: (a) 20-mm, (b) 40-mm, and (c) 60-mm cut with different flame cutting parameters.

\section{DISCUSSION}

Wear-resistant steel plates with thicknesses of 20, 40, and $60 \mathrm{~mm}$ were flame cut and characterized. The hardness and tensile strength properties were found to reduce as the thickness of the plates increases. The prior austenite grain size also increases with increasing plate thickness. The centerline microstructure of the $20-\mathrm{mm}$ plates consists of lath martensite. However, the microstructure of the $40-\mathrm{mm}$ plates consists of both bainite and martensite, and the $60-\mathrm{mm}$ plates consist mainly of bainite (with a small amount of lath martensite). The microstructures of the studied plates derive from the cooling conditions during the fabrication process. The cooling of thick plates is not necessarily as uniform and fast as that of thinner plates due to the increased thickness. This results in a partially bainitic structure or mainly bainitic structure in the centerline of the thicker plates and the morphology of microstructures are different, depending on the distance from the upper surface of the plate. The effect of different microstructures can also be seen in the hardness profiles measured in the thickness direction. The profiles showed that the hardness levels were generally higher and smoother in the thinnest plate and that the thicker plates contained more fluctuation near the centerline of the plates. The fluctuations seen in the hardness profiles are most likely due to the segregation that occurred during the manufacturing of the plates. ${ }^{[1]}$ The hardness results show that center segregation is the most severe in the $60-\mathrm{mm}$ plates and reduces with decreasing plate thickness. The amount of segregations increases with increasing plate thickness.

The impact toughness values are smaller in the $20-\mathrm{mm}$ plates than in the $40-\mathrm{mm}$ or $60-\mathrm{mm}$ plates $(0.5$ thickness). The explanation for this is the original microstructure on the centerline, which is lath martensite in the 20-mm plates, a mixture of bainite and lath martensite in the $40-\mathrm{mm}$ plates, and mainly bainite in the $60-\mathrm{mm}$ plates. It has been shown ${ }^{[19]}$ that martensite has inferior impact toughness properties than bainite and that the increasing volume fraction of bainite in the bainite-martensite structure increases the impact toughness. Generally, a small prior austenite grain size is known to induce the refinement of martensitic packets and blocks and therefore simultaneously to enhance the impact toughness. ${ }^{[20]}$ However, the formation of bainite 

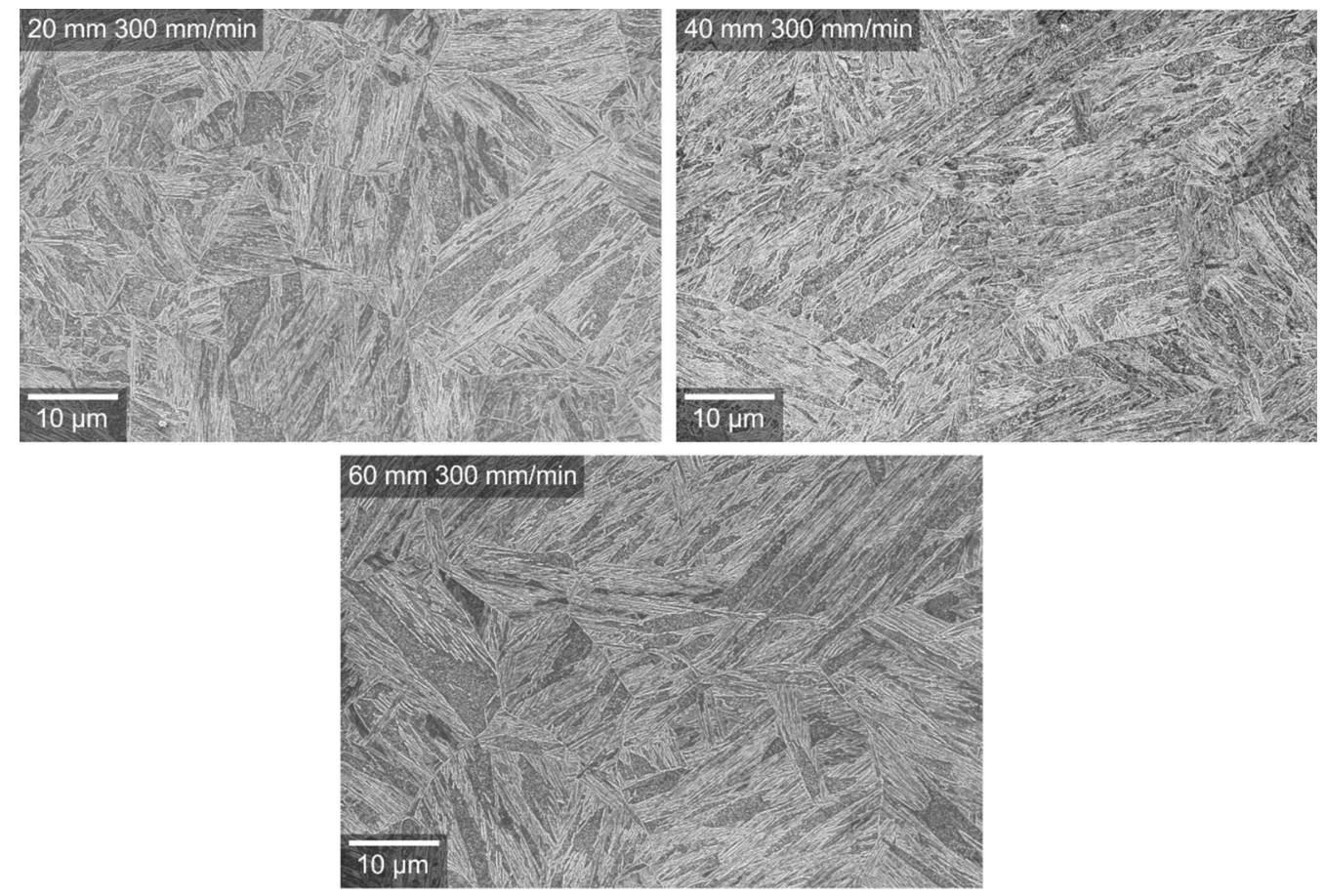

Fig. 9-Newly formed martensite regions of the $20-, 40-$, and $60-\mathrm{mm}$ plates produced by a $300-\mathrm{mm} / \mathrm{min}$ flame cutting speed. The images were from the centerline of the samples at a depth of $0.4 \mathrm{~mm}$.
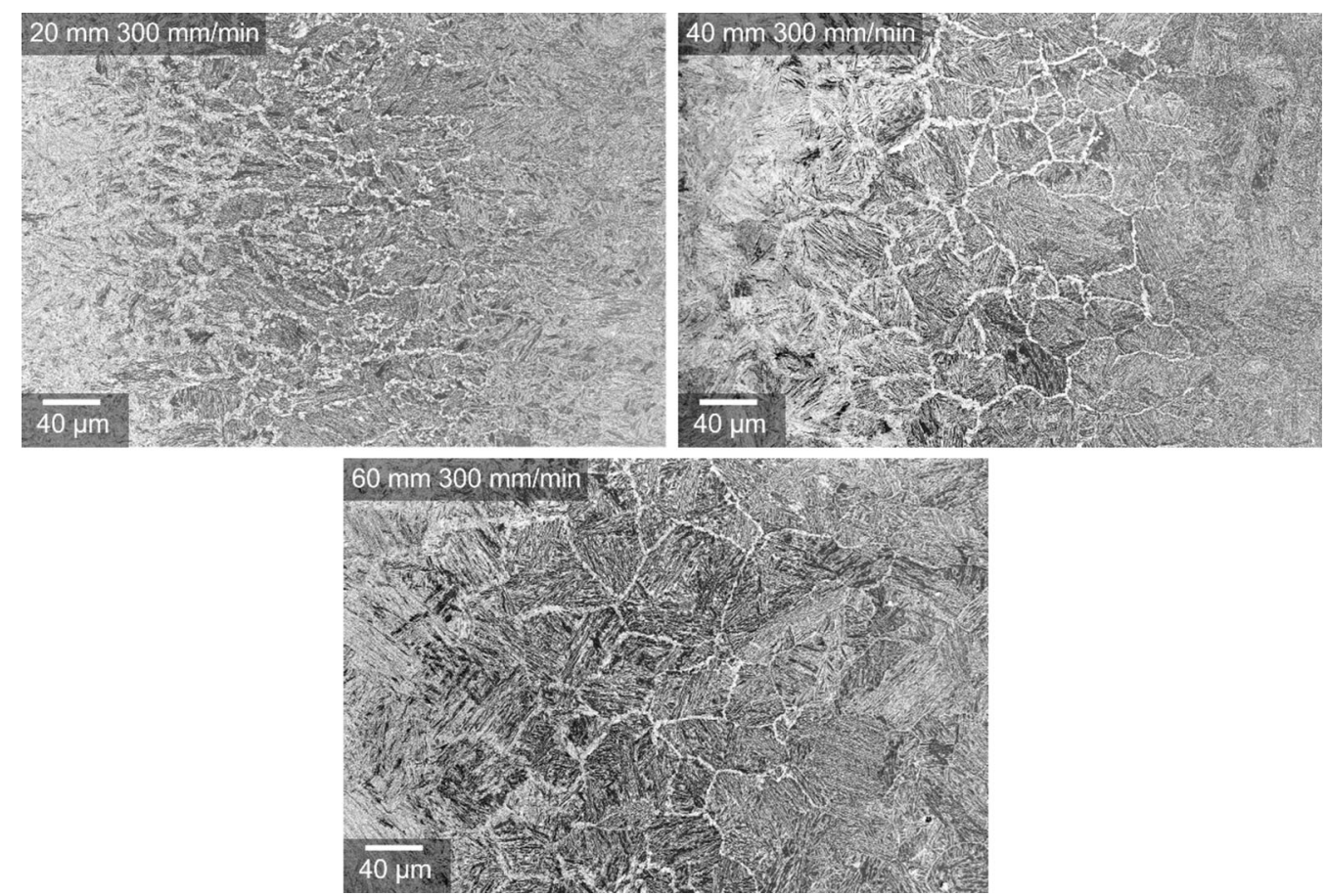

Fig. $10-$ Two-phase regions from the centerline of $20-, 40-$, and $60-\mathrm{mm}$ plates produced by a $300-\mathrm{mm} / \mathrm{min}$ flame cutting speed.

has also been shown ${ }^{[21]}$ to refine the subsequent martensitic packets and blocks. In the present study, the martensite structure in the 20 -mm plate results in lower impact toughness than the bainite-martensite structure of the $40-\mathrm{mm}$ plates and the mainly bainitic structure of the $60-\mathrm{mm}$ plates. In this case, the microstructure affects the impact toughness more than the prior austenite grain size $(20-\mathrm{mm}$ plates had smaller prior austenite grain size than the $40-$ or $60-\mathrm{mm}$ plates). However, it seems that the bainite structure of the $60-\mathrm{mm}$ plate has lower impact toughness in 0.5 thickness (in both the transverse and rolling directions) than does the 

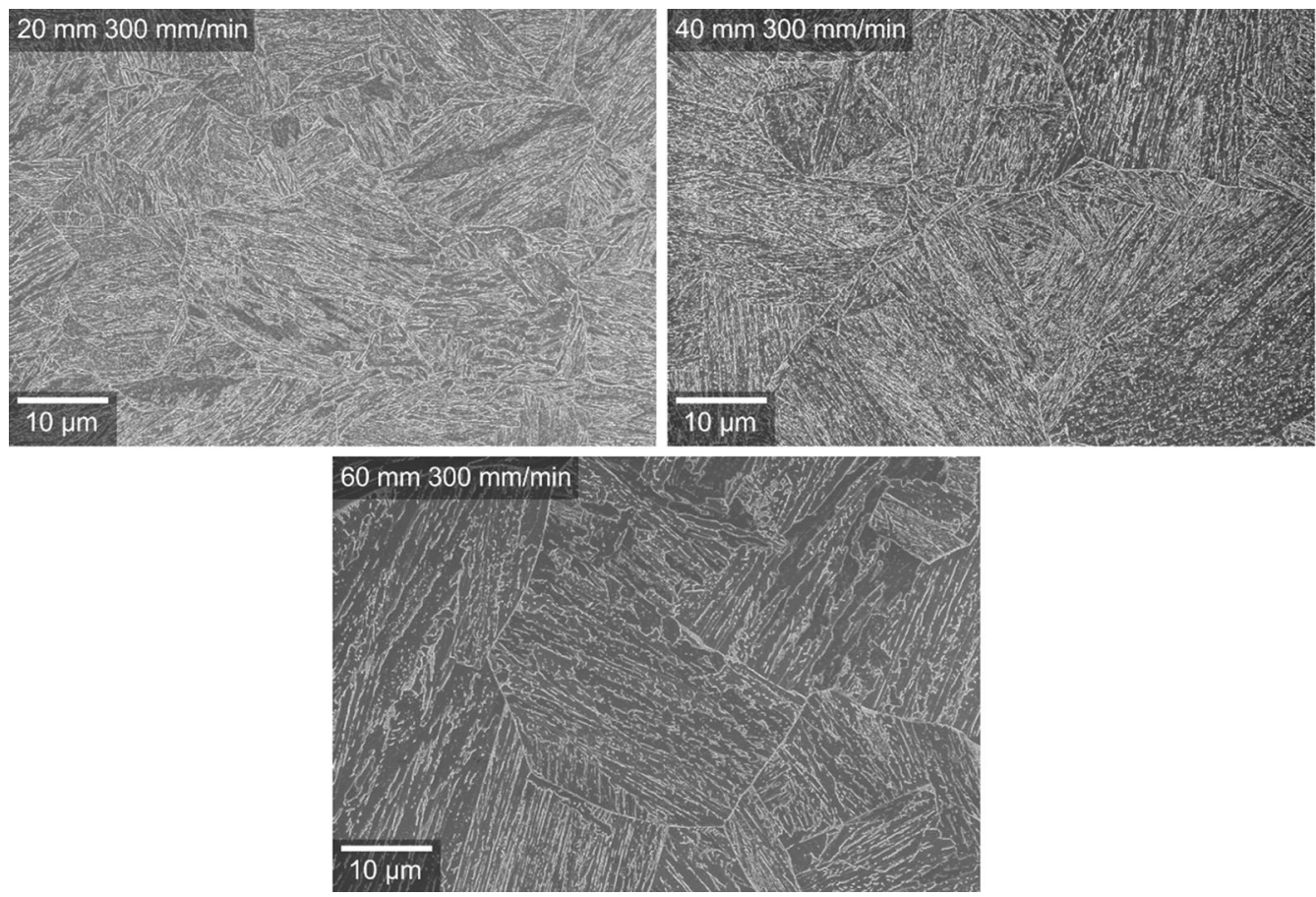

Fig. 11-Tempered regions (1.6 $\mathrm{mm}$ from the cut surface) of the $20-, 40-$, and $60-\mathrm{mm}$ plates formed at $300-\mathrm{mm} / \mathrm{min}$ cutting speed.

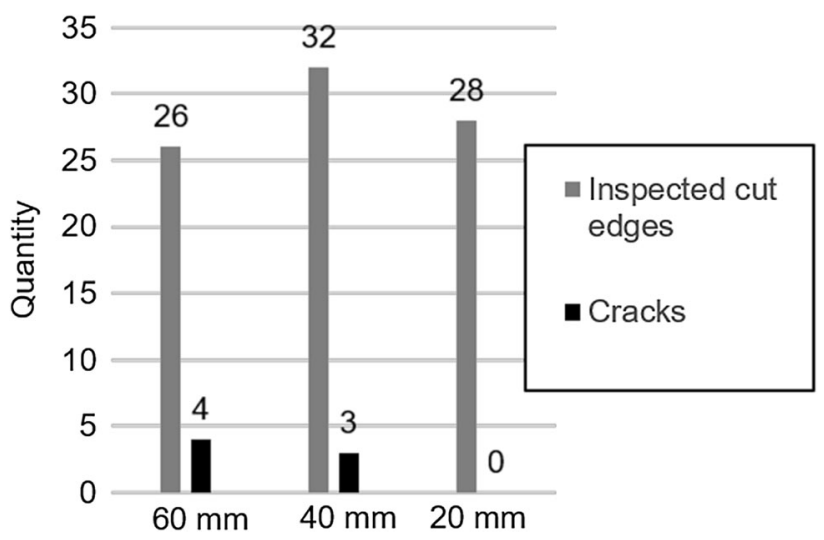

Fig. 12-Ultrasonic inspected flame cut samples of different plate thicknesses.

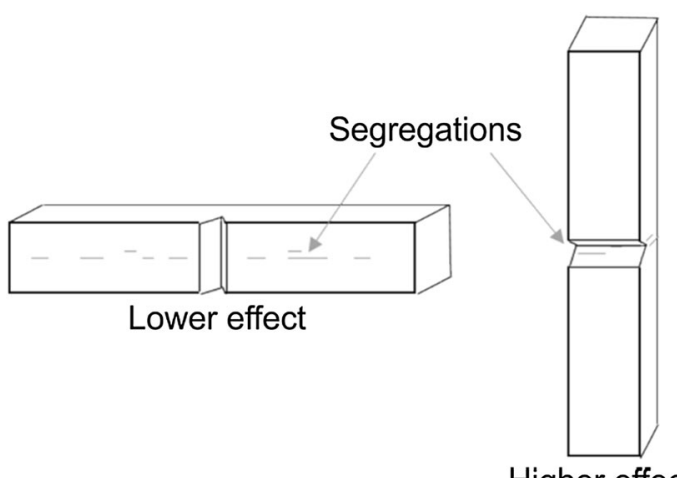

Higher effect

Fig. 13-Location of segregations relative to Charpy V-notch impact test specimens. bainite-martensite structure of the $40-\mathrm{mm}$ plates. In addition, the impact toughness of the 40- and $60-\mathrm{mm}$ plates varies depending on the distance from the upper surface. The 40-mm plates have higher impact toughness (rolling and transverse directions) in 0.5 thickness compared to 0.25 thickness. This might be due to the different cooling conditions at different depths of the plate during quenching. The 0.5 thickness of the plate cools more slowly compared to the 0.25 thickness, and consequently, the microstructures are different depending on the depth. As a result of the faster cooling, the microstructure of 0.25 thickness can be almost fully martensite while the slower cooling in the centerline produces a mixture of bainite and martensite. In contrast, the $60-\mathrm{mm}$ plates have better impact toughness in 0.25 thickness than in the centerline. Similarly to the 40-mm plates, the cooling conditions are different in 0.25 thickness and 0.5 thickness. However, with the $60-\mathrm{mm}$ plate, the cooling in 0.25 thickness is slower than in 0.25 thickness of the $40-\mathrm{mm}$ plates, and therefore, the resulting microstructure is a mixture of bainite and martensite. As the cooling of the 0.5 thickness is even slower, the produced microstructure in the centerline is mainly bainite. The large prior austenite grain size and segregations in the center region produce low impact toughness in the rolling and transverse directions at 0.5 thickness. Test results also show that impact toughness values are significantly lower in the thickness direction than in the transverse and rolling directions. A similar result was obtained by Wang et al. ${ }^{[3]}$ This can explained by the location of segregations relative to the test specimens as it is shown schematically in Figure 13. Segregations have a smaller effect in the rolling direction and the transverse direction in the middle section as 
their portion in the sample cross section is smaller. However, the effect increases in the through-thickness samples where the segregations cover more area in the test direction.

In addition, the impact toughness is lower in samples that had a notch in the segregation region than in samples that had a notch next to the segregation. Both impact toughness results and fracture surfaces indicate that the areas of segregation exhibit more brittle fracture behavior than do those next to the segregation. The reason for this might be the enrichment of the alloying elements, such as carbon, which locally increases the hardenability and makes the segregations more brittle compared to the regions next to them.

The residual stress measurements of flame cut surfaces show that the residual compressive stress decreases in the surface region $(<1 \mathrm{~mm})$ as the plate thickness increases. As a previous study ${ }^{[13]}$ has shown, a region of compressive stress is formed due to martensite transformation and the accompanying volume expansion occurring close to the cut edge. In addition, it has been shown ${ }^{[13]}$ that rapid and significant changes of temperature should be avoided during flame cutting as they create high thermal stresses in the cut edge of the plate before martensite transformation. One reason why thinner plates produce more compressive stress close to the cut surface than thick plates might be that the heating flame heats the cutting edge of the thin plates more than that of thicker ones. This heating acts similarly to preheating and lowers the temperature differences between the surface and interior. In contrast, the heating flame warms only the upper edge in thicker plates and does not create a similar preheating effect in the cut edge. However, this preheating effect from the heating flame in $20-\mathrm{mm}$ plates should not be confused with the actual preheating treatment carried out on the thicker plates (40 and $60 \mathrm{~mm}$ ). In addition, the heat transfer by conduction is higher in the thicker plates, which also increases the temperature difference between the surface and interior. As a result, the temperature difference is lower between the surface and interior during heating and cooling with thin plates, which leads to a lower thermal stress state before martensite transformation and eventually a lower final stress state after martensite transformation. In addition, a thin plate produced the lowest residual tensile stress values compared to thicker plates at a cutting speed of $150 \mathrm{~mm} /$ minute. However, as the cutting speed increases to 300 and $500 \mathrm{~mm} / \mathrm{minute}$, the tensile stress peak values are almost identical, with only small variations between the studied thicknesses. Residual stress measurements of 300 - and $500-\mathrm{mm} /$ minute cutting speeds indicate that plate thickness does not influence the tensile stress region as much at high cutting speeds compared to a lower cutting speed. A possible explanation for this is that as the cutting speed increases, large local variations in material temperature appear regardless of the plate thickness; i.e., even the thinnest plate is too thick for the temperature to equilibrate during high-speed cutting. However, in the case of higher cutting speeds, a very high speed of $700 \mathrm{~mm} /$ minute caused the lowest tensile stress region in the $20-\mathrm{mm}$ plate. In addition, the tensile stress peak at $700 \mathrm{~mm} /$ minute is not as wide as at 300 and $500 \mathrm{~mm} /$ minute. This might be due to the fact that the tempering effect (and the negative volume change during tempering) in the HAZ decreases as the cutting speed increases. From the residual stress point of view, these results indicate that a fast cutting speed is not necessarily the worst option for thinner plates. The results also indicate that low cutting speed and preheating have positive effects on the residual stress formation, as they increase the compressive stress in the surface and lower the tensile stress values. In addition, it can be seen that a lower cutting speed shifts the tensile stress region deeper into the subsurface. Preheating decreases the effect of the thermal shock that creates the thermal stresses by reducing the temperature differences inside the sample. ${ }^{[13]}$

As the earlier study ${ }^{[9]}$ by the current author showed, the HAZ consists of three regions: the newly formed martensite region, the two-phase region, and the tempered region. It was also shown that hardness profiles from the cut edge follow the microstructural regions of the cut edge. The extent of the microstructural regions depends more on the cutting parameters used than on the different plate thicknesses. A low cutting speed produces wider regions than a fast cutting speed, and different plate thicknesses cut with the same speed have almost similar width microstructural regions. All the studied plate thicknesses produced a high hardness martensite region close to the cut edge. In the two-phase region, the hardness is reduced as the newly formed martensite becomes mixed up with the tempered original structure. The two-phase regions of different plate thicknesses show that thinner plates contain more newly formed martensite and the amount of martensite decreases as the plate thickness increases. In addition, two-phase regions highlight the existing prior austenite grain boundaries as the austenization and martensitic transformations occur heterogeneously in prior austenite grain boundaries. The shape of the prior austenite grains is mostly equiaxed in all the studied plate thicknesses. However, the two-phase region also shows that the size of the prior austenite grains increases as the thickness of the plate increases. The lowest hardness occurs just after the two-phase region, and generally, the hardness values gradually increase toward the base material. However, in the $40-\mathrm{mm}$ plate, the hardness levels do not increase in the tempered region as much as in the $20-\mathrm{mm}$ plate, and the hardness values of the $60-\mathrm{mm}$ plates are almost constant after the two-phase region. The tempering effect is different between the steel thicknesses studied due to the different original microstructures of the studied plates. In the previous study, ${ }^{[9]}$ it was shown that tempering of martensite during flame cutting produced a fine structure of dispersed cementite $\left(\mathrm{Fe}_{3} \mathrm{C}\right)$ particles and that the tempering effect gradually decreased with increasing distance from the cut edge. However, it has been shown ${ }^{[22]}$ that there are significant differences in the tempering behavior of bainite and martensite. Unlike martensite, bainite contains only a small amount of carbon in solution as most of the carbon in the bainite structure is in cementite particles, which tend to be coarser than 
cementite in a tempered martensite structure. ${ }^{[23]}$ For this reason, a bainite structure exposed to elevated temperatures is less affected than martensite. Major changes in mechanical properties only occur when the bainite plate microstructure coarsens or recrystallizes into a structure of equiaxed grains of ferrite. ${ }^{[23]}$ Within the small amount of time available at elevated temperatures during the cutting process, sufficient coarsening of the cementite does not occur and therefore the mechanical properties of bainite do not change as much as in martensite. ${ }^{[22]}$ As the results show, the tempered region of the $20-\mathrm{mm}$ plates consists of a fine structure of dispersed cementite because the original structure contained purely lath martensite. Also, the tempered regions of the $40-\mathrm{mm}$ plates consist of finely dispersed cementite particles. However, the number of particles is somewhat less than in the $20-\mathrm{mm}$ plates and a small amount of coarsening of the cementite might also occur during tempering. The reason for this is that the original structure of the $40-\mathrm{mm}$ plate consists of a mixture of bainite and lath martensite. The fine cementite particles mostly originate from the martensite regions while the slight coarsening of the cementite occurs in the bainite regions. In the tempered regions of the $60-\mathrm{mm}$ plates, there are no similar dispersed cementite particles in the microstructure as in the tempered regions of the 20 - or $40-\mathrm{mm}$ plates. This is because the centerline microstructure of the $60-\mathrm{mm}$ plates consists mainly of bainite. The tempering may cause some slight coarsening of the existing cementite, which is difficult to distinguish. In addition, the hardness depth profiles of the $60-\mathrm{mm}$ plates show that the elevated temperatures during flame cutting do not affect the bainite structure as much as the martensitic structure. The hardness values are almost constant after the newly formed martensite region and the two-phase region. This indicates that there is not in fact a lower hardness region after the two-phase region because the tempering time is too short for bainite to influence the hardness levels. If the original structure is a mixture of bainite and martensite, as in the $40-\mathrm{mm}$ plates, tempering has an effect on the martensite regions but hardly any on the bainite regions. This can seen as decreased hardness values after the two-phase region and a slow increase in hardness values when going deeper into the subsurface.

Ultrasound inspection of the flame cut samples revealed no cracks in the $20-\mathrm{mm}$ plates. However, the cracking tendency is higher in thicker plates $(40-\mathrm{mm}$ plate: $1 \mathrm{crack} / 1600 \mathrm{~mm}$ and $60-\mathrm{mm}$ plate: $1 / 975 \mathrm{~mm}$ ). The inspection results indicate that thin plates withstand the residual stress state that is formed in flame cutting. In addition, most of the 40- and $60-\mathrm{mm}$ plates were found to be intact after flame cutting. However, since some cracks were detected in the 40 - and $60-\mathrm{mm}$ plates, it can be stated that on some occasions the residual stress levels are high enough for crack formation. In addition, the impact toughness results are significantly lower in the thickness direction compared to other directions. It was also observed that the 40 - and $60-\mathrm{mm}$ plates contained more segregations in the center region than did the $20-\mathrm{mm}$ plates. Thus, it seems that the cracks are commonly located in the segregations, which tend to be harder and more brittle than the base material. These results indicate that the susceptibility to cracking increases as the strong manufacturing-induced segregation occurring in the center region of thick plates is combined with the high residual tensile stress produced by high-speed flame cutting. However, all the tested steel plates exhibited ductile behavior macroscopically and most of the plates were found to be intact even in the presence of relatively large local residual tensile stresses. This highlights the stochastical nature of the cracking in flame cut steel plates. To lower the susceptibility to cracking, the residual tensile stresses should be lowered by utilizing the most optimal flame cutting parameters: low cutting speed and preheating. In addition, the formation of segregations should be avoided by improving manufacturing practices of thick plates.

\section{CONCLUSION}

Wear-resistant steel plates in three different thicknesses were investigated to study the effect of plate thickness on residual stress formation and cracking in flame cutting. The main conclusions of this study are summarized as follows:

1. Hardness and tensile strength properties reduce as the plate thickness increases. The centerline microstructure of thin plates is fully martensite, and the fraction of bainite increases with increasing thickness. The reason for this is that the centerline of thicker plates undergoes slower cooling during manufacturing. In addition, the hardness profiles in the thickness direction have more fluctuations in the center regions due to segregation as the plate thickness increases.

2. Thin plates have low impact toughness due to their fully martensitic microstructure. The impact toughness of thicker plates varies depending on the distance from the upper surface. Microstructures consisting of a mixture of bainite and martensite have the best impact toughness properties. Impact toughness in the thickness direction is significantly lower compared to the rolling and transverse directions. In addition, impact toughness is lower in segregation regions than in areas next to the segregation.

3. Flame cutting produces a hard martensite region close to the cut edge at all cutting speeds and all thicknesses. Hardness values decrease in the twophase region as the newly formed martensite mixes with the tempered original structure. The two-phase regions contain more newly formed martensite as the cutting speed and plate thickness reduce. The tempered regions of thin plates consisting of martensite produce a fine structure of dispersed cementite particles. However, the fine cementite particle structure diminishes in the tempered region 
as the bainite fraction increases with increasing thickness of the plates. The bainite is practically unchanged as the material is exposed to high elevated temperatures for only a short amount of time during flame cutting. Consequently, the hardness levels of thicker plates after the two-phase region are almost constant or slightly increased.

4. Residual stress measurements near the flame cut surfaces show that the residual compressive stress decreases in the surface region $(<1 \mathrm{~mm})$ as the plate thickness increases. A lower cutting speed causes a lower tensile stress region in the thin plates. However, the residual tensile stress values are almost the same at a higher cutting speed and for all thicknesses. In addition, a slow cutting speed and cutting with preheating have an advantageous effect on the residual stresses by increasing the compressive stress close to the surface and lowering the tensile stress deeper in the material.

5. Thicker plates tend to be more exposed to cracking. The susceptibility to cracking increases as the high residual stresses caused by flame cutting are combined with the manufacturing-induced, strong center segregation that occurs in thick plates. However, most plates were found to be intact even in the presence of relatively large local residual tensile stresses, and this highlights the stochastical nature of the cracking in flame cut steel plates.

\section{ACKNOWLEDGMENTS}

The work was mainly funded by the Tampere University of Technology graduate school. The authors would like thank Mr. Turo Salomaa for his considerable help with mechanical testing. Dr. Matti Isakov is gratefully acknowledged for his comments on the manuscript. This work made use of Tampere Microscopy Center facilities at Tampere University.

\section{OPEN ACCESS}

This article is distributed under the terms of the Creative Commons Attribution 4.0 International License (http://creativecommons.org/licenses/by/4.0/), which permits unrestricted use, distribution, and reproduction in any medium, provided you give appropriate credit to the original author(s) and the source, provide a link to the Creative Commons license, and indicate if changes were made.

\section{REFERENCES}

1. N. Yang, C. Su, X. Wang, and F. Bai: J. Construct. Steel Res., 2016, vol. 122, pp. 213-25.

2. Y. Wang, X. Liu, Z. Hu, and Y. Shi: Fatigue Fract. Eng. Mater. Struct., 2013, vol. 36, pp. 1258-73.

3. Y. Wang, X. Liao, Y. Zhang, and Y. Shi: J. Zhejiang Univ. Sci. A, 2015, vol. 16, pp. 217-28.

4. L.R. Soisson: Oxyfuel Gas Cutting, Welding, Brazing, and Soldering. ASM Handbook, ASM International, Materials Park, 1993, vol. 6, pp. 1155-65.

5. R. Thiébaud, J. Drezet, and J. Lebet: J. Mater. Process. Technol., 2014, vol. 214, pp. 304-10.

6. W. Wood: Report No. FHWA-RD-93-015, U.S. Department of Transportation, Federal Highway Administration, Virginia, 1994.

7. A. Martín-Meizoso, J. Aldazabal, J.L. Pedrejón, and S. Moreno: Fratt. Integrita Strutt., 2014, vol. 30, pp. 14-22.

8. A.D. Wilson: Eng. J., 1990, vol. 27, pp. 98-107.

9. T. Jokiaho, S. Santa-Aho, H. Järvinen, M. Honkanen, P. Peura, and M. Vippola: Mater. Perform. Charact., 2018, vol. 7, pp. 655-74.

10. P. Withers and H. Bhadeshia: Mater. Sci. Technol., 2001, vol. 17, pp. 355-65.

11. P. Withers and H. Bhadeshia: Mater. Sci. Technol., 2001, vol. 17, pp. 366-75.

12. L. Lindgren, A. Carlestam, and M. Jonsson: J. Eng. Mater. Technol., 1993, vol. 115, pp. 440-45.

13. T. Jokiaho, A. Laitinen, S. Santa-aho, M. Isakov, P. Peura, T. Saarinen, A. Lehtovaara, and M. Vippola: Metall. Mater. Trans. B, 2017, vol. 48B, pp. 2891-2901.

14. T. Jokiaho, T. Saarinen, S. Santa-Aho, P. Peura, and M. Vippola: Key Eng. Mater., 2016, vol. 674, pp. 103-08.

15. H. Bhadeshia and R. Honeycombe: Steels: Microstructure and Properties, 4th ed., Butterworth-Heinemann, Oxford, UK, 2017, pp. $387-88$.

16. EN 15305: Non-destructive Testing Method for Residual Stress analysis by X-ray Diffraction, 2008.

17. SFS-EN ISO 6892-1: Mechanical Engineering and Metals Industry Standardization in Finland, 2016,

18. SFS-EN ISO 148-1: Mechanical Engineering and Metals Industry Standardization in Finland, 2016.

19. K. Abbaszadeh, H. Saghafian, and S. Kheirandish: J. Mater. Sci. Technol., 2012, vol. 28, pp. 336-42.

20. C. Zhang, Q. Wang, J. Ren, R. Li, M. Wang, F. Zhang, and K. Sun: Mater. Sci. Eng. A, 2012, vol. 534, pp. 339-46.

21. T. Zhou, H. Yu, and S. Wang: Mater. Sci. Eng. A, 2016, vol. 658, pp. $150-58$

22. H. Bhadeshia: Bainite in Steels, 2nd ed., Institute of Materials, London, UK, 2001, pp. 91-116.

23. H. Bhadeshia and R. Honeycombe: Steels: Microstructure and Properties, 3rd ed., Butterworth-Heinemann, Oxford, UK, 2006, pp. 183-208.

Publisher's Note Springer Nature remains neutral with regard to jurisdictional claims in published maps and institutional affiliations. 